\title{
Development and evaluation of a sleep education program in middle school pupils based on self-determination theory
}

\author{
Christian Vollmer ${ }^{1}$, Judith Hammer ${ }^{1}$, Christian Keller ${ }^{1}$, Anna \\ Karina Maxand ${ }^{1}$, Juan Francisco Díaz-Morales ${ }^{2}$, \& Christoph \\ Randler $^{1}$
}

${ }^{1}$ University of Education Heidelberg, Institute of Science, Technology \& Geography, Im Neuenheimer Feld 561-2, D-69120 Heidelberg, 0049-6221-477-344, E-mail: randler@phheidelberg.de

${ }^{2}$ University Of Madrid, Work And Individual Differences Department, Faculty Of Psychology, Complutense, Campus De Madrid, Campus De Somosaguas, S/N, 28223, Madrid, Spain

\begin{abstract}
Education on sleep hygiene improves sleep knowledge. However, the literature shows that improvements in adolescents' sleep hygiene behaviour are less convincing. We developed an educational intervention for $6^{\text {th }}$ graders based on self-determination theory and evaluated this program in a pre-post-design with a control group. Pre-test was one week before the intervention, POST1 was directly afterwards, POST2 with a delay of one week, and POST3 after six weeks. Morningness was positively correlated with good sleep practice. The intervention increased pupils' theoretical sleep knowledge and knowledge about good sleep practices. However, their actual sleep practices did only improve in a short-term period but then became worse. We suggest that interventions might be longer and should last over the whole school year.
\end{abstract}

Key words: adolescents, sleep hygiene, sleep education, treatment-control study 


\section{Introduction}

Sleep is an often neglected topic in health education. Contemporary research has demonstrated that sleep is important for child and adolescent development (Buckhalt et al., 2009). With the onset of puberty, physiological and psychological changes delay sleep timing, also known as chronotype (Carskadon 1990, Crowley et al., 2007, Hagenauer et al., 2009, Randler et al., 2009). Although the actual sleep duration decreases in adolescence, this is not a result of decreased sleep need because sleep need (on average 9-10 h; Carskadon 2011) remains stable across adolescence (Tarokh et al., 2012; Thorleifsdottir et al., 2002). Since school starts early, sleep deprivation is epidemic in adolescents, and has consequences for cognitive and affective daytime functioning (Carskadon et al., 1998; Escribano et al., 2012, Randler \& Frech 2006, 2009).

Le Bourgeois et al. (2005) recommended sleep education to improve adolescents' sleep knowledge and practices and Buckhalt et al. (2009) recommended more treatment outcome studies.

Sleep education is effective. Previous sleep education programs yielded a consistent increase in sleep knowledge (Cortesi et al., 2004; Azevedo et al., 2008; Moseley \& Gradisar, 2009, Díaz-Morales et al., 2011). However, the results have not been convincing regarding changes in actual sleep hygiene behavior, changing of bed times and increase of sleep duration. Adachi et al. (2008) reported longer sleep duration and shorter sleep onset latency in Japanese workers after a simple behavioral intervention. University student's attendance of a sleep education program resulted in increased sleep quality and improved sleep hygiene behavior (e.g., reduced nap times; Tsai \& Li 2004; Brown et al., 2006). Concerning middle school pupils, Vo et al. (2003) reported improved sleep hygiene behavior (e.g., reduced social jetlag, longer sleep duration on schooldays). Adolescents' attendance of a sleep hygiene program resulted in reduced sleep irregularity, reduced sleep latency, and advanced nap-wake up schedule (Sousa et al., 2007); other studies showed a reduced discrepancy between school week and weekend out of bed times in the treatment group and less daytime sleepiness on weekends (Moseley \& Gradisar 2009; Rossi et al., 2002); further findings were improved self-management confidence over time, increased sleep quantity, as well as earlier bedtimes on school nights and weekends (Vo et al., 2003). However, Rossi et al. (2002) and Moseley and Gradisar (2009) found no decrease of sleep problems in general after the treatment with school lessons, albeit a reduced social jetlag for evening types.

In general, there is a paucity of educational programs and studies about the effectiveness of teaching and learning about sleep in secondary school pupils. Most programs are delivered by medical or biology students rather than by educational psychologists, and Mosely \& Gradisar (2009) for example explicitly mentioned the role of motivation in developing further school based programs. Thus, an educational program dealing with the aspects of sleep hygiene should focus on motivational aspects, and should start before the pubertal drift to eveningness occurs. We developed a school intervention by consulting both, experts in chronobiology and experts in education to design a program that follows the selfdetermination theory of motivation (Deci \& Ryan, 1985). 


\section{Methodology}

\section{Educational Program}

We developed short educational programs (1.5h each) on dreaming education and on sleep education. The program about dreaming was used as a control group. The sleep intervention program covered physiological facts about sleep, morningness-eveningness, and good sleep practice, that is, sleep hygiene behaviour. Both educational programs followed the selfdetermination theory as explicated by Deci and Ryan $(1985,1991)$. According to Deci and Ryan (1985, 1991), humans have three basic needs:

- $\quad$ experiencing competency,

- autonomy,

- $\quad$ and social relatedness.

In general, autonomy experience should allow pupils to exert some control over their learning process, that is, they should be enabled to choose some of their work freely and to work on their own. While working in a self-directed manner, pupils experience competence because they themselves acquire the knowledge. This could be achieved, for example, by working in work stations (Schaal \& Bogner, 2005). Further, social relatedness inevitably requires some kind of learning in groups, which has also been found to be superior over single work or teacher-centred work (Lou et al. 1996). Therefore, the basis of the educational program was grounded in this learning theory (see also Ryan, 2012). A high level of perceived competency and autonomy leads to an intrinsically motivated behaviour (Ryan \& Deci, 2000; 2002) which increases learning success. Social relatedness is an additional factor for intrinsic motivation (Ryan \& Deci, 2002). Some studies showed that a high level of selfdetermination positively influences learning processes (e.g. Grolnick \& Ryan, 1987; Connell \& Wellborn, 1991).

Both programs were similar in their structure. Teachers started the lessons with reading parts of a book or listening to a play, followed by a plenary discussion, work in small groups, learning circuits (or workstations) and a concluding plenary discussion. Pupils worked together in groups of 3-4 which is considered an optimal group size (Lou et al., 1996).

\section{Development of questionnaires}

In order to measure the effect of sleep education on sleep knowledge and sleep practices, the pupils filled out questionnaires. Cognitive achievement in sleep knowledge (6 items), knowledge about good sleep practices (10 items) and intended/actual sleep practices (10 items) were measured using a pre-/post-test design based on paper-pencil-tests (table 1). 
Table 1. Items from the questionnaire

\section{Items}

Answers with coding

(1) Lack of sleep impairs attention (for example: in road traffic); (2) Subjects learned are memorized while being asleep; (3) Sleep quality depends on the ambient temperature; (4) While asleep, the brain is shut down like a computer (negative coding); (5) More or less than eight hours of sleep is unhealthy (negative coding); (6) In the morning, humans are equally alert at the same time (negative coding).

(1) After dinner, I snack (for example, crisps, sweets) (negative coding); (2) After dinner, I have drinks with caffeine (for example: cola, iced tea)* (negative coding); (3) During the 1 hour before bedtime, I do things that make me relaxed or tired (for example: reading, listening to quiet music or a play); (4) During the 1 hour before bedtime, I do things that make me feel very awake (for example: playing video games, watching television, talking on the telephone)* (negative coding); (5) I go to bed with a stomachache* (negative coding); (6) I fall asleep in a darkened room; (7) I fall asleep in a room that feels too hot or too cold.* (negative coding); (8) I have breakfast at home before school; (9) In the morning, I have enough time to leave home without haste; (10) I get fresh air on the way to school.

* Le Bourgeois et al. (2005)

The sleep knowledge (cognitive achievement) and sleep practice (actual behavior) questionnaires were developed by an expert rating based on science educators from a University and a psychologist and have a high face-validity. Some questions were taken from Le Bourgeois et al. (2005; see table 1). Cronbach's $\alpha$ of the respective sleep practices tests were 0.508 (PRE), 0.544 (POST1), 0.617 (POST2) and 0.542 (POST3). Sleep knowledge and sleep practices were measured repeatedly in control and treatment groups: seven days before intervention (PRE) and at three points after the intervention - immediately afterwards (POST1), seven days afterwards (POST2) and six weeks afterwards (POST3). The pupils provided coded personal information to track their questionnaires through the four waves. 


\section{Further measurements}

Further, we measured chronotype (Composite Scale of Morningness (CSM), Smith et al., 1989) as well as bed- and rise clock times before the intervention and six weeks afterwards to calculate a proxy of midpoint of sleep.

\section{Participants and data collection}

The school intervention took place in 12 classes ( 6 treatment, 6 control) between 16 and 31 May 2011. All pupils were $6^{\text {th }}$ graders of the same type of school (Realschule). The study was approved by the research committee at the University of Education Heidelberg and the relevant school authorities (file number 71c2-6499.25). Written consent was obtained from the parents. Further, all principals and teachers agreed to participate in this study. Informed consent was obtained from all pupils. The study was anonymous, voluntary and unpaid.

\section{Statistical analysis}

Cronbach's alpha was used to assess the internal consistency of the questionnaires (reliability) in SPSS. In dichotomous items, SPSS calculates the alpha level based on the KuderRichardson-formula-20. We used Pearson's correlations and a general linear model (MANOVA) with pre-test values for sleep knowledge, knowledge about good sleep practices and sleep practices as co-variates, gender as well as treatment as fixed factors, and post-test values for sleep knowledge and sleep practice as dependent factors (table 3). Thus, the dreaming education group served as a control group for the sleep-hygiene program. We checked the Levene test for homogeneity of variances and the assumption was that there was homogeneity ( $p>0.1$ for sleep knowledge, but significant for knowledge of sleep practice). We used two-sided t-tests, because this is standard usage although current textbooks suggest that two-sided tests should be used when the direction of the effect is not a priori clear. We could expect both, differences in the one and the other direction when comparing the two groups (treatment versus control).

\section{Results}

279 pupils participated in this study: 143 boys and 136 girls, spread equally over dreaming education $(n=139)$ and sleep education $(n=140)$ groups. Mean age was $12.51(S D \pm 0.46)$. Means and standard deviations for other study variables are provided in table 2 (below).

Prior to the intervention (PRE), there were no gender differences in sleep knowledge, knowledge about good sleep practices, and sleep practices. Chronotype prior to the intervention (PRE) was not correlated with sleep knowledge and knowledge about good sleep practices, but correlated with sleep practices: morning-types had better sleep hygiene practice $(\mathrm{r}=0.293, \mathrm{p}<0.001)$. 
Table 2. Means and standard deviations

\begin{tabular}{lccc}
\hline & & M & SD \pm \\
\hline Age & PRE & 12.51 & 0.46 \\
PRE Chronotype (CSM) & PRE & 35.25 & 6.42 \\
PRE Midpoint of sleep (MSFsc) & PRE & $03: 57 \mathrm{am}$ & $01: 05 \mathrm{~h}$ \\
PRE Sleep duration on school days & PRE & $09: 04 \mathrm{~h}$ & $0: 50 \mathrm{~h}$ \\
PRE Sleep duration on weekends & PRE & $10: 00 \mathrm{~h}$ & $1: 42 \mathrm{~h}$ \\
PRE Social jetlag & PRE & $2: 22 \mathrm{~h}$ & $0: 58 \mathrm{~h}$ \\
\hline & PRE & 2.61 & 1.83 \\
Sleep knowledge & POST1 & 3.16 & 1.81 \\
& POST2 & 3.30 & 1.72 \\
& POST3 & 3.23 & 1.70 \\
\hline & PRE & 3.71 & 1.58 \\
Knowledge about good sleep practices & POST1 & 4.14 & 1.29 \\
& POST2 & 3.98 & 1.62 \\
& POST3 & 4.05 & 1.33 \\
\hline Sleep practices & PRE & 3.86 & 2.89 \\
\hline Intended sleep practices & POST1 & 4.29 & 2.93 \\
\hline Sleep practices & POST2 & 3.90 & 3.22 \\
\hline
\end{tabular}

Chronotype (CSM): on a scale from morning-type =13 to evening-type = 55; Midpoint of sleep, see Roenneberg et al. (2004); social jetlag, see Wittmann et al. (2006), sleep knowledge: measured on a scale from -6 to 6 with higher values indicating more correct answers; knowledge about good sleep practices: measured on a scale from -5 to 5 with higher values indicating more correct answers; (intended) sleep practices: measured on a scale from -10 to 10 with higher values indicating better sleep practices.

The sleep intervention (treatment group) increased pupils' sleep knowledge. Knowledge about good sleep practices was already high before the intervention and became higher afterwards. There was a positive treatment effect on sleep practices one week afterwards, which disappeared after six weeks. Reported sleep hygiene behaviour (sleep practice) was generally low.

Concerning the MANOVA (table 3), the sleep education (treatment) group gained more sleep knowledge than the dreaming education (control) group and this disparity remained highly significant $(\mathrm{p}<0.001)$ after one week (POST2) and still after six weeks (POST3). The differences in knowledge about good sleep practices were less distinct and a significantly greater increase in the treatment group was visible after one week $(p=0.029)$ and after six weeks $(p=0.028)$. The sleep education group reported significantly better sleep practices only in POST2 $(\mathrm{p}=0.020)$. 
Table 3. MANOVA, treatment -> sleep knowledge, sleep practices

\begin{tabular}{|c|c|c|c|c|c|c|c|c|c|c|c|c|}
\hline & & \multicolumn{2}{|c|}{ Treatment } & \multicolumn{2}{|c|}{ Gender } & \multicolumn{2}{|c|}{$\begin{array}{c}\text { PRE } \\
\text { Sleep knowledge }\end{array}$} & \multicolumn{2}{|c|}{$\begin{array}{c}\text { PRE } \\
\text { Knowledge } \\
\text { about good sleep } \\
\text { practices }\end{array}$} & \multicolumn{2}{|c|}{$\begin{array}{c}\text { PRE } \\
\text { Sleep practices }\end{array}$} & \\
\hline & & 0.869 & 4.437 & 0.935 & 2.036 & 0.759 & 9.342 & 0.895 & 3.462 & 0.625 & 17.668 & \\
\hline Dependent variables: & & $\mathrm{p}$ & $\begin{array}{c}\text { Partial } \\
\eta^{2}\end{array}$ & $\mathrm{p}$ & $\begin{array}{c}\text { Partial } \\
\eta^{2}\end{array}$ & $\mathrm{p}$ & $\begin{array}{c}\text { Partial } \\
\eta^{2}\end{array}$ & $\mathrm{p}$ & $\begin{array}{c}\text { Partial } \\
\eta^{2}\end{array}$ & $\mathrm{p}$ & $\begin{array}{c}\text { Partial } \\
\eta^{2}\end{array}$ & $\begin{array}{l}\text { Adjusted } \\
\mathrm{R}^{2}\end{array}$ \\
\hline \multirow[t]{2}{*}{ Sleep knowledge } & POST2 & $<0.001$ & 0.065 & 0.017 & 0.021 & $<0.001$ & 0.090 & 0.927 & 0.000 & 0.540 & 0.001 & 0.152 \\
\hline & POST3 & $<0.001$ & 0.056 & 0.011 & 0.024 & $<0.001$ & 0.080 & 0.565 & 0.001 & 0.922 & 0.000 & 0.139 \\
\hline \multirow{2}{*}{$\begin{array}{l}\text { Knowledge about } \\
\text { good sleep practices }\end{array}$} & POST1 & 0.362 & 0.003 & 0.067 & 0.012 & 0.723 & 0.000 & 0.002 & 0.033 & 0.019 & 0.020 & 0.087 \\
\hline & POST2 & 0.029 & 0.017 & 0.652 & 0.001 & 0.048 & 0.014 & $<0.001$ & 0.078 & 0.229 & 0.005 & 0.142 \\
\hline \multirow{2}{*}{ Sleep practices } & POST2 & 0.020 & 0.020 & 0.142 & 0.008 & 0.223 & 0.005 & 0.008 & 0.026 & $<0.001$ & 0.150 & 0.251 \\
\hline & POST3 & 0.513 & 0.002 & 0.166 & 0.007 & 0.246 & 0.005 & 0.705 & 0.001 & $<0.001$ & 0.289 & 0.317 \\
\hline
\end{tabular}

$\mathrm{n}=279$; Treatment: 0 = dreaming education (control group), 1 = sleep education (treatment group); PRE: seven days before intervention; POST1: immediately afterwards; POST2: seven days afterwards; POST3: six weeks afterwards; sleep knowledge: measured on a scale from -6 to 6 with higher values indicating more correct answers; knowledge about good sleep practices: measured on a scale from -5 to 5 with higher values indicating more correct answers; (intended) sleep practices: measured on a scale from -10 to 10 with higher values indicating better sleep practices. 
Girls were able to retain sleep knowledge longer than boys; they scored significantly higher than boys after one week $(p=0.017)$ and after six weeks $(p=0.011)$. Also, the girls' intention to enhance their sleep practices was higher than the boys' $(p=0.018)$. There were no gender differences in knowledge about good sleep practices.

The intervention had no effect on POST3 chronotype (Smith et al., 1989), POST3 midpoint of sleep (Roenneberg et al., 2004), POST3 social jetlag (Wittmann et al., 2006) or POST3 sleep duration.

\section{Discussion}

We can confirm the feasibility of a school intervention in increasing sleep knowledge (de Sousa et al., 2007; Azevedo et al., 2008; Cain et al., 2011). The educational interventions, thus, proved to be highly effective in terms of cognitive learning. From an educational perspective, gaining knowledge is an important step to develop and change attitude and behavior (Kaiser, Roczen \& Bogner, 2008). We recommended basing the educational programs on self-directed learning following the motivational theory of Deci \& Ryan (2000) to increase learning effects, rather than giving simple lectures. However, in contrast to other studies (Vo et al., 2003; Tsai \& Li 2004; Brown et al., 2006) and in line with Cortesi et al. (2004), Moseley and Gradisar (2009) and Rossi et al. (2002), the influence of the teaching on our pupils' actual sleep practices was small and only temporarily. Thus we conclude that the increase in knowledge did not improve adolescents' sleep habits. Although their knowledge about good sleep practices - especially when compared to their sleep knowledge - was high and increased with the intervention, good sleep practices were not common and mean values of sleep practice were surprisingly low already in our $6^{\text {th }}$ graders. The results show that $6^{\text {th }}$ graders have already developed a bad sleep hygiene behaviour. We assume that physiological predispositions and adaption of new social roles at the start of puberty are too strong to mitigate the adolescent drift to eveningness with a school intervention program. Regarding gender, in contrast to previous studies (Adan et al., 2006) girls did not show better sleep hygiene practice.

In contrast to Moseley \& Gradisar (2009), we found no changes in several sleep variables (chronotype, midpoint of sleep, social jetlag, and sleep duration).

Since pupils were asked to answer the same questionnaire four times, the scales of the questionnaire were considerably short, and thus had a rather low Cronbach's $\alpha$, which is a limitation of our study. Also, participating schools and pupils were not selected randomly. However, we kept the sample homogeneous by only allowing one type of school (Realschule) to participate.

Further programs should aim for a change in behaviour. However, to our knowledge, there are only a handful of programs dealing with sleep hygiene. In addition, most - if not all -of these educational programs are based on a teacher-centred approach rather than on a sound pedagogical theory. Maybe the effect of the intervention would have been higher if we 
accompanied the pupils over a longer period of time. We urge future studies to track changes of sleep practices and chronotype longitudinally into puberty. Future studies should implement a more extensive school intervention in an earlier grade $\left(5^{\text {th }}\right.$ grade) before the pubertal drift to eveningness around the age of 12-13 years (Randler et al., 2009) occurs. Future studies should focus on motivating students to maintain these changes over time using several resources such as: promoting activities in the daytime, regular dinner times, light control using dawn simulators (Thorn et al., 2004; Giménez et al., 2010; Fromm et al., 2011), explaining the impact of caffeine, alcohol, cigarettes and sweets (Kanerva et al., 2012) and of electronic screen media use before bedtime on sleep (Vollmer et al., 2012), introducing relaxing sleep rituals, a dark and quiet bedroom and consistent bedtimes, avoidance of long naps, and offering sleep education sessions for parents (Kryger et al., 2000; Cain et al., 2011) because parental monitoring of bedtimes during the week exerts a significant influence on morningness-eveningness (Randler et al., 2009). Since changes in behaviour are hard to achieve in general and especially with a school intervention, we recommend later school start times for older pupils (cf. Wahlstrom 2002; Carskadon 2004; Klein 2004; Hansen et al., 2005; Noland et al., 2009).

As expected in research on teaching and learning, we found a substantial influence of the pre-test knowledge on the subsequent tests. This is found in many studies because Ausubel (1968) already noticed "The most important single factor influencing learning is what the learner already knows."

\section{Acknowledgments}

We would like to thank principals, teachers, parents and $6^{\text {th }}$ graders from DietrichBonnhoeffer-Realschule Weinheim, Johannes-Kepler-Realschule Heidelberg, TheodorHeuss-Realschule Walldorf, Feudenheim-Realschule Mannheim, and Seckenheim-Realschule Mannheim.

\section{References}

Adachi, Y., Sato, C., Kunitsuka, K., Hayama, J., \& Doi, Y. (2008). A brief behavior therapy administered by correspondence improves sleep and sleep-related behavior in poor sleepers. Sleep and Biological Rhythms, 6, 16-21.

Adan, A., Fabbri, M., Natale, V., \& Prat, G. (2006). Sleep Beliefs Scale (SBS) and circadian typology. Journal of Sleep Research, 15, 125-132.

Arendt, J. (2006). Melatonin and human rhythms. Chronobiology International, 23, 21-37.

Ausubel, D.P. (1968). Educational Psychology: A Cognitive View. New York: Holt, Rinehart \& Winston.

Azevedo, C.V.M., Sousa, I., Ketema, P., McLeish, M. Y., Mondéjar, M. T., Sarabia, J. A., Rol, M. A., \& Madrid, J. A. (2008). Teaching Chronobiology and sleep habits in school and University. Mind, Brain and Education, 2, 34-47.

Brown, F. C., Buboltz, W. C., \& Soper, B. (2006). Development and evaluation of the sleep treatment and education program for students (STEPS). Journal of American College Health, 54, 231-237. 
Buckhalt, J. A., El-Sheikh, M., \& Wolfson, A. R. (2009). Children's sleep and school psychology practice. School Psychology Quarterly, 24, 60-69.

Cain, N., Gradisar, M., \& Moseley, L. M. (2011). A motivational school-based intervention for adolescent sleep problems. Sleep Medicine, 12, 246-251.

Carskadon, M. A., Harvey, K., Duke, P., Andres, T. F., Litt, I. F., \& Dement, W.C. (1980). Pubertal changes in daytime sleepiness. Sleep, 2, 453-460.

Carskadon, M. A. (1990). Patterns of sleep and sleepiness in adolescents. Pediatrician, 17, 5-12.

Carskadon, M. A., Wolfson, A. R., Acebo, C., Tzischinsky, O., \& Seifer, R. (1998). Adolescent sleep patterns, circadian timing, and sleepiness at a transition to early school days. Sleep, 21, 871-881.

Carskadon, M. A. (2004). Sleep deprivation: health consequences and societal impact. Medical Clinics of North America, 88, 767-776.

Carskadon, M. A. (2011). Sleep in adolescents: The perfect storm. Pediatric Clinics of North America, 58, 637647.

Connell, J. P., \& Wellborn, J. G. (1991). Competence, autonomy, and relatedness: A motivational analysis of self-system processes. In M. R. Gunnar \& L. A. Sroufe (Eds.), Self processes and development. The Minnesota symposium on child psychology. (pp. 43-77). Hillsdale, NJ : Lawrence Erlbaum Associates, Inc.

Crowley, S. J., Acebo, C., \& Carskadon, M. A. (2007). Sleep, circadian rhythms, and delayed phase in adolescence. Sleep Medicine, 8, 602-612.

Deci, E. L., \& Ryan, R. M. (1985). Intrinsic motivation and self-determination in human behavior. New York: Plenum Press.

Deci, E. L., \& Ryan, R. M. (1991). A motivational approach to self: Integration in personality. In R. Dienstbier (Ed.), Nebraska Symposium on Motivation: Vol. 38: Perspectives on Motivation (pp.237-288). Lincoln, NE.: University of Nebraska Press.

Díaz-Morales, J. F., Prieto, P. D., Barreno, C. E., Mateo, J. C., \& Randler, C. (2011). Sleep beliefs and chronotype among adolescents: the effect of a sleep education program. Biological Rhythm Research, 43, 397-412.

Digdon, N. (2010). Circadian preference and college students' beliefs about sleep education. Chronobiology International, 27, 297-317.

Escribano, C., Díaz-Morales, J. F., Delgado, P., \& Collado, M. J. (2012). Morningness/eveningness and school performance among Spanish adolescents: Further evidence. Learning and Individual Differences, 22, 409-413.

Fromm, E., Horlebein, C., Meergans, A., Niesner, M., \& Randler, C. (2011). Evaluation of a wake-up light in children and adolescents. Biological Rhythm Research, 42, 417-425.

Gallasch, J. (2007). Relationships between sleep knowledge, sleep practice and sleep quality. Sleep and Biological Rhythms, 5, 63-73.

Giannotti, F., Cortesi, F., Sebastiani, T., \& Ottaviano, S. (2002). Circadian preference, sleep and daytime behavior in adolescence. Journal of Sleep Research, 11, 191-199.

Giménez, MC., Hessels, M., van de Werken, M., Vries, B. de, Beersma, D. G. M., \& Gordijn, M. C. M. (2010). Effects of artificial dawn on subjective ratings of sleep inertia and dim light melatonin onset. Chronobiology International, 27, 1219-1241.

Grolnick, W. S., \& Ryan, R. M. (1987). Autonomy in children's learning: An experimental and individual difference investigation. Journal of Personality and Social Psychology, 52, 890-898.

Hagenauer, M. H., Perryman, J., Lee, T. M., \& Carskadon, M. A. (2009). Adolescent changes in the homeostatic and circadian regulation of sleep. Developmental Neuroscience, 31, 276-284.

Hansen, M., Janssen, I., Schiff, A., Zee, P. C., \& Dubocovich ML (2005). The Impact of School Daily Schedule on Adolescent Sleep. Pediatrics, 115, 1555-1561.

Kaiser, F. G., Roczen, N., \& Bogner, F. X. (2008). Competence formation in environmental education: advancing ecology-specific rather than general abilities. Umweltpsychologie, 12, 56-70.

Kanerva, N., Kronholm, E., Partonen, T., Ovaskainen, M. L., Kaartinen, N. E., Konttinen, H., Broms, U., \& Männistö, S. (2012). Tendency toward eveningness is associated with unhealthy dietary habits. Chronobiology International, 29, 920-927. 
Klein, J. (2004). Planning middle school schedules for improved attention and achievement. Scandinavian Journal of Educational Research, 48, 441-450.

Kryger, M. H., Roth, T., \& Dement, W. (2000). Principles and practice of sleep medicine. 3rd ed. Philadelphia (PA): WB Saunders.

LeBourgeois, M. K., Giannotti, F., Cortesi, F., Wolfson, A. R., \& Harsh, J. (2005). The relationship between reported sleep quality and sleep hygiene in Italian and American adolescents. Pediatrics, 115, 257-265.

Lou, V., Abrami, P. C., Spence, J. C., Poulsen, C., Chambers, B., \& d'Apollonia, S. (1996). Within-class grouping: a meta-analysis. Review of Educational Research, 66, 423-458

Moseley, L., Psyc, M., \& Gradisar, M. (2009). Evaluation of a School-Based Intervention for Adolescent Sleep Problems. Sleep, 32, 334-341.

Noland, H., Price, J. H., Dake, J., \& Telljohann, S. K. (2009). Adolescents' sleep behaviors and percep-tions of sleep. Journal of School Health, 79, 224-230.

Randler, C. (2008). Differences in sleep and circadian preference between eastern and western German adolescents. Chronobiology International, 25, 565-575.

Randler, C., \& Frech, D. (2006). Correlation between morningness - eveningness and final school leaving exams. Biological Rhythm Research, 37, 233-239.

Randler, C., \& Frech, D. (2009). Young people's time-of-day preferences affect their school performance. Journal of Youth Studies, 12, 651-665.

Randler, C., Bilger, S., \& Díaz-Morales, J. F. (2009). Association between sleep, chronotype, parental monitoring and pubertal development in German adolescents. The Journal of Psychology, 143, 509-520.

Roenneberg, T., Kuehnle, T., Pramstaller, P., Ricken, J., Havel, M., Guth, A., \& Merrow, M. (2004). A marker for the end of adolescence. Current Biology, 14, 1038-R1039.

Rossi, C. M., Campbell, A. L., Vo, O. T., Marco, C. A., \& Wolfson, A. R. (2002). Middle school sleep-smart program: a pilot evaluation. Sleep, 25, A279.

Ryan, R. M. (2012). The Oxford Handbook on Human Motivation. Oxford University Press: Oxford.

Ryan, R. M., \& Deci, E. L. (2000). Self-Determination Theory and the Facilitation of Intrinsic Motivation, Social Development, and Well-Being. American Psychologist, 55, 68-78.

Ryan, R. M., \& Deci, E. L. (2002). An overview of self-determination theory. In E. L. Deci \& R. M. Ryan (Eds.), Handbook of self-determination research (pp. 3-33). Rochester, NY: University of Rochester Press.

Schaal, S \& Bogner, F (2005). Human visual perception - learning at workstations. Journal of Biological Education, 40, 32-37.

Smith, C. S., Reilly, T. C., \& Midkiff, K. (1989). Evaluation of three circadian rhythm questionnaires with suggestions for an improved measure of morningness. Journal of Applied Psychology, 74, 728-738.

Sousa, I. C., Araujo, J. F., \& Azevedo, C. V. M. (2007). The effect of a sleep hygiene program on the sleep-wake cycle of Brazilian adolescent students. Sleep and Biological Rhythms, 5, 251-258.

Tarokh, L., Carskadon, M. A., \& Achermann, P. (2012). Dissipation of sleep pressure is stable across adolescence. Neuroscience, 216, 167-177.

Thorleifsdottir, B., Björnsson, J. K., Benediktsdottir, B., Gislason, T., \& Kristbjarnarson, H. (2002). Sleep and sleep habits from childhood to young adulthood over a 10-year period. Journal of Psychosomatic Research, 53, 529-537.

Thorn, L., Hucklebridge, F., Esgate, A., Evans, P., \& Clow, A. (2004). The effect of dawn simulation on the cortisol response to awakening in healthy participants. Psychoneuroendocrinology, 29, 925-930.

Tsai, L. L., \& Li, S. P. (2004). Sleep education in college: a preliminary study. Perceptual \& Motor Skills, 99, 837-848.

Vo, O. T., LeChasseur, K., Wolfson, A., \& Marco, C. (2003). Sleepy pre-teens: second pilot of Sleep-Smart Program in 7th graders. Sleep, 26, A411.

Vollmer, C., Michel, U., \& Randler, C. (2012). Outdoor light at night (LAN) is correlated with eveningness in adolescents. Chronobiology International, 29, 502-508.

Wahlstrom, K. (2002). Accomodating the sleep patterns of adolescents within current educational structures: an uncharted path. In Carskadon, M. A. (Ed.), Adolescent sleep patterns. Biological, social, and psychological influences (pp. 172-197). Cambridge, Cambridge University Press. 
International Journal of Biology Education

Vol. 3, Issue 1, March 2014

Wittmann, M., Dinich, J., Merrow, M., \& Roenneberg, T. (2006). Social jetlag: misalignment of biological and social time. Chronobiology International, 23, 497-509. 